\title{
Cancer as a channelopathy: ion channels and pumps in tumor development and progression
}

\author{
Alisa Litan and Sigrid A. Langhans * \\ Nemours Center for Childhood Cancer Research, Alfred I. duPont Hospital for Children, Wilmington, DE, USA
}

Increasing evidence suggests that ion channels and pumps not only regulate membrane potential, ion homeostasis, and electric signaling in excitable cells but also play important roles in cell proliferation, migration, apoptosis and differentiation. Consistent with a role in cell signaling, channel proteins and ion pumps can form macromolecular complexes with growth factors, and cell adhesion and other signaling molecules. And while cancer is still not being cataloged as a channelopathy, as the non-traditional roles of ion pumps and channels are being recognized, it is increasingly being suggested that ion channels and ion pumps contribute to cancer progression. Cancer cell migration requires the regulation of adhesion complexes between migrating cells and surrounding extracellular

\section{OPEN ACCESS}

Edited by: Maria Cristina D'Adamo, University of Perugia, Italy

Reviewed by: Annarosa Arcangeli, University of Florence, Italy Christian Stock University of Muenster, Germany Luigi Catacuzzeno, University of Perugia, Italy

*Correspondence: Sigrid A. Langhans, Nemours Center for Childhood Cancer Research, Alfred I. duPont Hospital for Children, Rockland Center I, 1701 Rockland Road, Wilmington, DE 19803, USA Tel: 302-651-6538

Fax: 302-651-4827 langhans@nemoursresearch.org

Received: 23 December 2014 Accepted: 23 February 2015 Published: 17 March 2015

Citation: Litan A and Langhans SA (2015) Cancer as a channelopathy: ion channels and pumps in tumor development and progression. Front. Cell. Neurosci. 9:86. doi: 10.3389/fncel.2015.00086 matrix (ECM) proteins. Cell movement along solid surfaces requires a sequence of cell protrusions and retractions that mainly depend on regulation of the actin cytoskeleton along with contribution of microtubules and molecular motor proteins such as mysoin. This process is triggered and modulated by a combination of environmental signals, which are sensed and integrated by membrane receptors, including integrins and cadherins. Membrane receptors transduce these signals into downstream signaling pathways, often involving the Rho GTPase protein family. These pathways regulate the cytoskeletal rearrangements necessary for proper timing of adhesion, contraction and detachment of cells in order to find their way through extracellular spaces. Migration and adhesion involve continuous modulation of cell motility, shape and volume, in which ion channels and pumps play major roles. Research on cancer cells suggests that certain ion channels may be involved in aberrant tumor growth and channel inhibitors often lead to growth arrest. This review will describe recent research into the role of ion pumps and ion channels in cell migration and adhesion, and how they may contribute to tumor development.

Keywords: sodium channel, potassium channel, Na-K-ATPase, migration, actin, signaling

\section{Introduction}

Cancer is a leading cause of death worldwide. According to the American Cancer Society, more than 1.6 million new cases were diagnosed in 2013, and one in four deaths in the US is cancer related. Most cancers are treated with surgery, chemotherapy, and/or radiation therapy. Although these clinical measures have proven their efficacy in many cases, patients often experience debilitating side effects that significantly reduce their quality of life. Moreover, cancer relapse 
with treatment resistance underscores the urgent need to identify novel molecular targets for the development of alternative therapies. Recently, the role of ion channels in driving malignant cancer cell behavior has been revealed and much has been learned from brain tumors (Figure 1). Changes in channel expression have been observed primarily in glioblastoma, the most aggressive malignant brain tumor arising from astrocytes (Sontheimer, 2008) and have also been seen in medulloblastoma, the most common pediatric brain tumor that originates in the cerebellum (Hatten and Roussel, 2011). With our increasing knowledge of ion channels and pumps in tumor development cancer is being classified as a channelopathy, or a disease brought about by disturbed function of ion channels, often due to dysregulation of channel expression (transcriptional channelopathy) or other modifications resulting in altered function (Pedersen and Stock, 2013; Djamgoz et al., 2014) (and articles therein).

The proteins that transport ions across cell membranes fall into two general classes: ion channels, through which ions move down their concentration and electrical gradients, and ion pumps that use energy to actively move ions against those gradients (Gadsby, 2009). About 13\% of currently known drugs whose primary therapeutic targets are ion channels are being used for the treatment of a variety of human conditions, including cardiovascular and neurological disorders (Overington et al., 2006). Some examples include lidocaine, a local anesthetic that targets sodium channels, verapamil, a drug used to treat hypertension and targets calcium channels, riluzole which is used to treat amyotrophic lateral sclerosis and targets sodium channels, and the class of drugs that target sodium channels in the brain to treat epilepsy such as carbamazepine and topiramate (Camerino et al., 2007). With our evolving understanding of the molecular mechanisms of channelopathies, ion channels have now become a promising player for the development of novel anticancer therapies. In this review we will discuss a variety of classes of channels and pumps and their relationship to cancer development and progression including sodium, potassium, chloride, and calcium channels, and ion transport pumps.

\section{Overview of Ion Channels and Pumps with Dysregulated Expression in Cancer Cells}

\section{Potassium Channels}

Potassium channels can be divided into four classes based on their domain structure and activation mechanisms. Voltagegated potassium channels $(\mathrm{Kv})$ are the largest subset of potassium channels, and they are gated by changes in membrane potential. Calcium-activated potassium channels (KCa) are activated by intracellular calcium. According to their conductance, $\mathrm{KCa}$ channels can be further divided into big conductance (BK), intermediate conductance (IK), and small conductance (SK) channels. KV and KCa channels share a similar structure-they are composed of four pore-lining $\alpha$-subunits, each with six transmembrane domains and one pore-forming region, except for the BK channel, which has

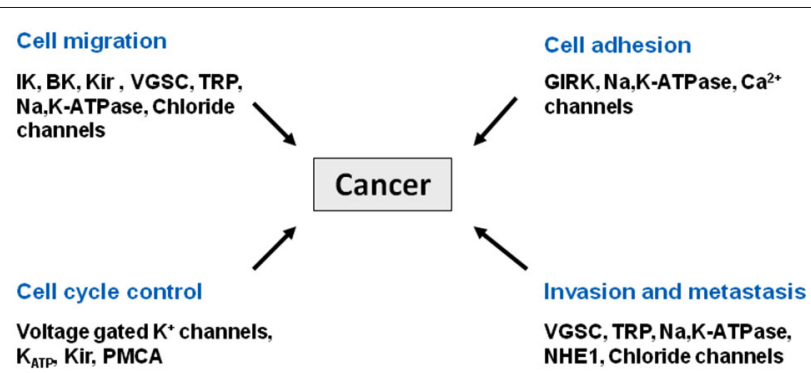

FIGURE 1 | Cancer as a channelopathy. Mutations, loss of expression/function and aberrant expression/function of ion channels and transporters have been linked to various cancers. Aberrant cell migration, cell adhesion, and cell cycle control all contribute to the invasive phenotype associated with metastasis.

one additional transmembrane segment in the $\mathrm{N}$ terminus. Transmembrane regions 1-4 represent the voltage-sensing domains for $\mathrm{Kv}$ channels (Huang and Jan, 2014). Inward rectifying potassium channels (Kir) possess two transmembrane segments flanking one pore loop in each of the four $\alpha$-subunits. Two-pore domain potassium channels (K2P) have two pore domains per $\alpha$-subunit. Two $\alpha$-subunits form a K2P channel that is usually constitutively open as a "leak channel" for maintaining a negative membrane potential (Huang and Jan, 2014). Multiple studies have reported dysregulated potassium channel expression in human cancer. Overexpression of $\mathrm{K}_{\mathrm{V}} 1.1$ is seen in medulloblastoma (Northcott et al., 2012), elevated $\mathrm{K}_{\mathrm{V}} 1.3$ can be detected in multiple malignancies including breast, colon, and prostate cancer (Comes et al., 2013), and overexpression of a specific splice variant of the BK channel correlates with the malignancy grade of glioma (Liu et al., 2002). Altered expression of the intermediate-conductance calcium activated channel KCa3.1 has also been shown in glioblastoma (Catacuzzeno et al., 2012). $K_{V} 1.5$ channels are dysregulated in multiple cancers including lymphomas, astrocytomas, oligodendrogliomas, and glioblastomas (Comes et al., 2014). Expression levels of $K_{V} 10.1$ (EAG1, voltage gated eag related subfamily $H$, member 1 ) are lower in glioblastoma multiforme and in malignant brain tumors than in normal brain tissue, and expression of the EAG1 channel is inversely related to malignancy of the tumor (Patt et al., 2004). Human ether-a-go-go related gene (hERG) $\mathrm{K}^{+}$channel, also known as $\mathrm{K}_{\mathrm{V}} 11.1$, is constitutively expressed in neuroblastoma, and a molecular complex between $\beta_{1}$-integrins and hERG channels regulates adhesion-dependent differentiation of neuroblastoma cells (Cherubini et al., 2005). And expression of Kir4.1 channels in glioma cells impaired cell growth (Higashimori and Sontheimer, 2007).

\section{Sodium Channels and Exchangers}

Voltage gated sodium channels (VGSCs) are responsible for the rising phase of the action potential in the majority of electrically excitable cells and are therefore important in impulse generation and propagation. VGSCs comprise a multi-gene family of at least nine different functional members $\left(\mathrm{Na}_{\mathrm{V}} 1.1-1.9\right)$ coding for the pore-forming $\alpha$-subunits. There are also four 
auxiliary $\beta$-subunits, of which one or two at a time can associate with an $\alpha$-subunit and modulate channel expression and activity in the plasma membrane. Recently, VGSCs have been found to have relatively high expression levels in a range of cell types that are considered non excitable, including immune cells, fibroblasts and cancer cells (Brackenbury, 2012). Moreover, several individual $\mathrm{Na}_{\mathrm{V}}$ isoforms are differentially expressed in different human cancers. These include $\mathrm{Na}_{V} 1.5$ in astrocytoma, breast and colon cancers (Chioni et al., 2010; Brisson et al., 2013; Driffort et al., 2014; Xing et al., 2014), $\mathrm{Na}_{V} 1.6$ in cervical cancer, and $\mathrm{Na}_{\mathrm{V}} 1.7$ in breast, prostate and non-small cell lung cancers (Fraser et al., 2014). Another group of sodium channels is the epithelial sodium channel family, located in the apical membrane of polarized epithelial cells. High grade gliomas express multiple members of the epithelial sodium channel family, and there is an elevated expression of the acid-sensing ion channel 1 (ASIC1) in glioblastoma cells compared to primary astrocytes (Kapoor et al., 2009).

In addition to these sodium channel families, there is also a group of exchanger proteins that involve transport of sodium ions. Some of these exchanger proteins include the $\mathrm{Na}^{+} / \mathrm{H}^{+}$exchanger (NHE1), the $\mathrm{Na}^{+}, \mathrm{HCO}_{3}^{-}$contransporter, and the $\mathrm{Na}^{+}, \mathrm{K}^{+}, 2 \mathrm{Cl}^{-}$cotransporter (NKCC). All of these proteins utilize the $\mathrm{Na}^{+}$electrochemical gradient to drive the transport of other ions, and they are all important in maintaining cellular $\mathrm{pH}$. The NHE1 is a ubiquitously expressed transporter that contributes to cell volume regulation and cytoplasmic $\mathrm{pH}$ homeostasis. In cancer NHE1 is upregulated and/or overexpressed in various tumors and plays a fundamental role in malignant invasion by altering the metabolic environment and cell invasiveness (Cardone et al., 2005; Stock et al., 2012). For example, NHE is involved in breast cancer and melanoma invasion and metastasis (Stüwe et al., 2007; Amith and Fliegel, 2013; Vahle et al., 2014) indicating that NHE1 may be a suitable target for anticancer therapy (Stock et al., 2012). Aside from NHE1, additional exchangers have been shown to be affected in cancer. For example, the $\mathrm{Na}^{+} / \mathrm{HCO}_{3}^{-}$contransporter is upregulated by human epidermal growth factor receptor 2 (HER2) signaling in breast cancer cells (Gorbatenko et al., 2014), and NKCC modulates glioma cell migration through regulation of focal adhesions and cell volume (Garzon-Muvdi et al., 2012).

\section{Chloride Channels}

The CLC and the cystic fibrosis transmembrane conductance regulator (CFTR) channels are distinct classes of chloride channels. Functions of chloride channels range from ion homeostasis to cell volume regulation and regulation of excitable cells. These channels have 10-12 transmembrane domains, and are found both in the plasma membrane and the membranes of various organelles. Dysregulation of chloride channels has been reported in multiple cancer types. Expression of CLCA1 and CLCA2 is downregulated in human colorectal cancer, revealing a possible tumor suppressor role for these proteins (Bustin et al., 2001). Changes in glioma-specific chloride current are linked to the cell cytoskeleton, and cytoskeletal rearrangements associated with cell division lead to change in chloride channel activity (Ullrich and Sontheimer, 1997), and regulate glioblastoma cell invasiveness (Turner and Sontheimer, 2014).

\section{Calcium Channels}

$\mathrm{Ca}^{2+}$ is a ubiquitous second messenger, and is an important signaling molecule for several fundamental cell processes including cell cycle control, migration, and apoptosis. Some human diseases that have been associated with $\mathrm{Ca}^{2+}$ homeostasis include cancer, Alzheimer's disease, and cardiovascular disease (Chen et al., 2013). Regulation of intracellular $\mathrm{Ca}^{2+}$ involves both $\mathrm{Ca}^{2+}$ entry from the extracellular space and $\mathrm{Ca}^{2+}$ release from intracellular stores in the endoplasmic reticulum (ER) or mitochondria. Calcium channels not only allow facilitated diffusion of $\mathrm{Ca}^{2+}$ down its concentration gradient, they also provide for the flow of $\mathrm{Ca}^{2+}$ out of the ER into the cell cytosol through $\mathrm{ER} \mathrm{Ca}^{2+}$ channels. Plasma membrane channels involved in the influx of $\mathrm{Ca}^{2+}$ into the cell include voltage-gated $\mathrm{Ca}^{2+}$ and transient receptor potential (TRP) ion channels. There are multiple types of calcium channels that are differentially regulated in various cancer types. TRPC 3 is elevated in some breast and ovarian tumors, and its silencing reduces ovarian cancer cell line proliferation in vitro and tumor formation in vivo (Aydar et al., 2009). TRPC6 expression is elevated in breast, liver, and stomach cancers and in glioma. Silencing of TRPC6 reduces proliferation of some esophageal and breast cancer cell lines and glioma cells (Ding et al., 2010). The expression level of TRPM7 and formation of metastases are positively correlated in breast cancer, suggesting that TRPM7 contributes to a migratory and invasive phenotype. T-type voltage gated $\mathrm{Ca}^{2+}$ channels are expressed in normal tissues as well as in various cancers such as breast carcinoma, retinoblastoma, neuroblastoma, and glioma (Zhang et al., 2014). Increased expression of the $\alpha 1$ subunit of T-type channels contributes to abnormal proliferation of glioblastoma cells, siRNA-mediated knockdown of the $\alpha 1$ subunit decreases proliferation of these cells, and pharmacological blockade of T-type channels decreases tumor growth (Zhang et al., 2014).

\section{Ion Exchangers}

The P-type ATPases are a major class of ion pumps and are characterized by an aspartate residue in the cytoplasmic domain that gets phosphorylated by ATP once transported ions have entered the binding pocket (Gadsby, 2009). Some examples of P-type ATPases are the Sodium potassium ATPase (Na,K-ATPase), the sarcoplasmic and endoplasmic reticulum Ca-ATPase (SERCA), the H,K-ATPase and the H-ATPase. To date, the best characterized pumps that have been linked to cancer are SERCA and the Na,K-ATPase. SERCA ATPases are important regulators of intracellular calcium concentration. They enable muscle contraction and relaxation, and control calcium signaling pathways (Yatime et al., 2009). SERCA also has recently been identified as a therapeutic target in certain types of cancer. SERCA inhibition induces a G0/G1 arrest in NOTCH1-mutated human leukemia cells, introducing SERCA 
as a potential therapeutic target in cancers associated with NOTCH1 mutations (Roti et al., 2013). SERCA inhibition through a thapsigargin prodrug is being tested as a potential treatment for prostate cancer by inducing apoptosis (Denmeade et al., 2003). The Na,K-ATPase is a ubiquitously expressed integral membrane protein that carries out the extrusion and uptake of $\mathrm{Na}^{+}$and $\mathrm{K}^{+}$ions across the plasma membranes of cells of most higher eukaryotes. It is composed of a catalytic $\alpha$-subunit with ten transmembrane segments and a heavily glycosylated $\beta$-subunit. The pump is critical in maintaining a physiological electrochemical gradient that is essential for cell survival and for many cellular activities. Na,K-ATPase is highly expressed in glioblastoma cells (Mijatovic et al., 2008). Decreased expression of Na,K-ATPase $\beta_{1}$-subunit has also been reported in various cancers (Rajasekaran et al., 1999, 2001; Espineda et al., 2003, 2004; Seligson et al., 2008; Rajasekaran and Rajasekaran, 2009). The effect of the Na,K-ATPase has also been studied in glioblastoma cells. Treatment with digoxin and ouabain, both specific Na,K-ATPase inhibitors, resulted in impaired proliferation in glioblastoma cell lines and the same cells exhibited an apoptotic phenotype (Joshi et al., 2011). Along with the identification of its differential expression in cancer cells and its important roles in cell survival, proliferation, adhesion and migration, the clinical potential of $\mathrm{Na}, \mathrm{K}$-ATPase modulators such as cardiac glycosides in oncology has drawn increasing interest in recent years (Newman et al., 2008; Prassas and Diamandis, 2008; Menger et al., 2012; Alevizopoulos et al., 2014; Wolle et al., 2014).

\section{Ion Carriers, Ion Channels and Ion Pumps in Cancer Cell Migration}

Ion channels and pumps are the targets of many intracellular signaling pathways and can function as signal transducers themselves. Nearly every type of voltage-gated $\mathrm{K}^{+}, \mathrm{Ca}^{2+}$, and $\mathrm{Na}^{+}$channel is regulated to some extent by phosphorylation of serine, threonine, or tyrosine residues on intracellular domains of the channel (Ismailov and Benos, 1995). Phosphorylation can alter channel gating properties, including voltage sensitivity and calcium sensitivity, thereby potentially altering the electrophysiological properties of a cell. While initially only studied in excitable cells, ion channels are now known to be important in supporting the basic biology of malignant and non-malignant cells including cell proliferation and tumor cell migration. The ability of cancer cells to migrate allows them to change position within the body and invade other tissues. As a primary tumor grows, it must undergo angiogenesis in order to support its metabolic needs. New blood vessels can also provide a route by which tumor cells can migrate through the body's circulatory system, into a distant organ or tissue (Chambers et al., 2002). Tumor cells use migration mechanisms that are similar, if not identical to those in normal cells during normal physiological processes such as embryogenesis, wound healing, and neuronal migration. Migration requires cells to modify their shape and stiffness to interact with surrounding tissue, and results from a continuous cycle of interdependent steps. First, a moving cell becomes polarized, and, through Rac activation, a protrusion of the lamellipodium is formed at the cell's leading edge, which attaches to the extracellular matrix (ECM). Next, regions of the cell body contract, generating a force that leads to movement of the cell (Schwartz and Horwitz, 2006). Invasive cancer cells develop similar invadopodia to explore and invade the surrounding ECM. Both the outgrowth of lamellipodia or invadopodia and the retraction of the rear end of the cell require local swelling and shrinkage, respectively. These changes in cell volume are regulated by local ion transport through the $\mathrm{NHE} 1$, the $\mathrm{Na}^{+}, \mathrm{HCO}_{3}^{-}$contransporter, the $\mathrm{Na}^{+}, \mathrm{K}^{+}, 2 \mathrm{Cl}^{-}$ cotransporter, chloride channels at the leading edge and tip of the outgrowing lamellipodium/invadopodium (Schwab et al., 1999; Stroka et al., 2014; Turner and Sontheimer, 2014). In breast cancer cells, repetitive cycles of local, NHE1-dependent swelling at the cell front and shrinkage at the rear end enable cells to move independently of actin polymerization and integrinmediated adhesion. This may be the mechanism underlying the rounded tumor cell migration that allows cell movement through dense ECM without matrix degradation (Friedl and Alexander, 2011).

\section{Potassium Channels}

The best characterized functions of potassium channels in facilitating cell migration are related to their ability to cause volume changes by affecting potassium flow (see (Turner and Sontheimer, 2014) for a comprehensive review). An early study linking potassium channels to cell migration was on transformed Madin-Darby canine kidney (MDCK-F) renal epithelial cell migration. The authors showed that specific application of the IK channel blocker charybdotoxin to the trailing edge, but not the leading edge, inhibits migration and increases overall cell volume (Schwab et al., 1999). Their results revealed that inhibition and activation of the IK channel elicited nearly identical effects on migration, F-actin content and intracellular calcium concentration as anisosmotic cell swelling or shrinkage. Since IK channel inhibition or activation elicits similar volume changes as anisotonicity, the authors suggested that cell volume is a link between $\mathrm{K}^{+}$channel activity, the actin cytoskeleton and migration (Schwab et al., 1999). More recent studies showed that genetic suppression or pharmacological inhibition of BK channels impairs glioma cell migration. Specifically, Weaver et al. (2006) found that inhibition of BK channels reduced glioma cell migration across a transwell filter, suggesting that $\mathrm{K}^{+}$efflux is essential for glioma cell migration. Interestingly, chronic application of a BK channel opener also resulted in impaired glioma cell migration, demonstrating the importance of controlling potassium channel activity for proper cell movement (Kraft et al., 2003). Another important potassium channel involved with cell migration is KCa3.1 (Sciaccaluga et al., 2010; Catacuzzeno et al., 2011, 2012), an IK channel involved in retraction of the cell's trailing edge for forward movement (Schwab et al., 2012). Inhibition of KCa3.1 disrupts glioma cell chemotaxis towards multiple ligands (Cuddapah et al., 2013). Moreover Clotrimazole, a KCa3.1 channel blocker inhibits the growth of glioblastoma cells by arresting cells at the G1-S transition, and delays development of intracranial glioblastoma tumor formation (Liu et al., 2010). The SK channel was shown to control constitutive $\mathrm{Ca}^{2+}$ entry and cancer cell migration 
through interaction with the $\mathrm{Ca}^{2+}$ channel Ora1 in lipid rafts. Localization of the SK-Oral complex was essential to control cancer cell migration, and co-localization of the two channels was found in primary human tumors and bone metastases (Chantôme et al., 2013). Potassium channels can also regulate cancer cell migration via non-canonical functions. For example, the $\mathrm{K}_{\mathrm{V}} 11.1$ (HERG) channel can form a macromolecular complex with vascular endothelial growth factor receptor (VEGFR)-1 and $\beta_{1}$-integrin, and assembly of this complex confers a pro-migratory phenotype in leukemia (Pillozzi et al., 2002). Colocalization of $\alpha_{9} \beta_{1}$ integrin with the Kir4.2 channel in focal adhesions at the leading edge of migrating cells can promote local Kir4.2 channel activity to induce formation of a lamellipodium extension for migration. Moreover, the Kir channel inhibitor barium, or knockdown of the subunit Kir4.2, specifically inhibited $\alpha_{9}$-dependent cell migration (deHart et al., 2008; Schwab and Stock, 2014).

\section{Sodium Channels}

Expression of VGSCs has been associated with cell motility and metastatic behavior. Grimes et al. (1995) found that the strongly metastatic Mat-LyLu cell line expressed VGSCs, while the related but weakly metastatic AT-2 cell line did not. Interestingly, incubation of the Mat-Ly-Lu cell line with tetrodotoxin, a specific VGSC blocker, reduced the invasive capacity of the cells in vitro. A similar pattern was found in analogous human prostate cancer cell lines PC-3 and human prostate adenocarcinoma (LNCaP), respectively (Laniado et al., 1997). Both Nav1.6 and $\mathrm{Na}_{\mathrm{V}} 1.7$ were significantly upregulated in prostate cancer cell lines (Shan et al., 2014). In vitro experiments have also shown that tetrodotoxin inhibits cancer invasion, proliferation and migration in PC-3 prostate cancer cells (Shan et al., 2014). More specifically, the effects of VGSC $\alpha$ - and $\beta$-subunit expression individually have been researched in various cancers. Expression of the VGSC $\alpha$-subunit has been reported in several cancers including breast cancer, prostate cancer, neuroblastoma, and glioma (Brackenbury, 2012). In some of these malignancies, $\alpha$ subunit protein and mRNA expression correlated with metastatic potential. For example, VGSC was found to increase in line with metastatic potential in the $\mathrm{LNCaP}$ progression model of prostate cancer cells (Bennett et al., 2004). Conversely, in gliomas, the mRNA level of VGSC $\alpha$-subunits is inversely correlated with malignancy grade (Schrey et al., 2002). The role of VGSC $\beta$ subunits has also been investigated. The $\beta_{1}$-subunit is highly expressed in weakly metastatic breast cancer (MCF-7) cells, and it enhances adhesion while inhibiting migration in a transwell assay (Chioni et al., 2009). On the other hand, much lower levels of $\beta_{1}$ were found in strongly metastatic breast cancer MDA-MB231 cells. Overexpression of $\beta_{1}$ in these cells increased cell-cell adhesion, induced process outgrowth, and reduced migration in wound healing assays (Chioni et al., 2009). Overexpression of $\beta_{2}$ in LNCaP cells increased adhesion, process outgrowth, migration, and invasion (Jansson et al., 2012). Thus, it seems that $\beta_{1}$ and $\beta_{2}$ play slightly different functional roles in different cancer cells. It is important to note that $\beta$-subunits play a critical role in regulating adhesion and migration in excitable cells like neurons, where they are normally expressed. For example, $\beta_{1}$ enhances neurite outgrowth and neuronal path finding during early postnatal development of the central nervous system (Davis et al., 2004). $\beta_{1}$-mediated neurite outgrowth in cerebellar granule cells requires fyn kinase, the cell adhesion molecule contactin, and is dependent on $\mathrm{Na}_{V} 1.6$ activity (Brackenbury et al., 2008).

\section{Chloride Channels}

Chloride channels are critical in maintaining cell volume, and therefore play an important role in regulating migration of cancer cells. Migratory glioma cells are elongated, suggesting that invading glioma cells undergo cell volume changes to move through the extracellular space (Sontheimer, 2004). Blocking $\mathrm{Cl}^{-}$channels inhibits changes in cell volume and inhibits cell migration (Watkins and Sontheimer, 2011). Inhibition of NKCC1, which maintains an outward gradient for $\mathrm{Cl}^{-}$, also impairs motility of glioma cells in vitro (Haas and Sontheimer, 2010). Non-specific $\mathrm{Cl}^{-}$channel inhibitors decrease cell migration in vitro (Soroceanu et al., 1999). However more specifically, shRNA mediated knockdown of ClC-3 decreased in vitro glioma cell migration (Cuddapah and Sontheimer, 2010) and Chlorotoxin, which reduces membrane expression of ClC-3, inhibited migration in vitro and in vivo (Sontheimer, 2008).

\section{Calcium Channels}

Changes in intracellular $\mathrm{Ca}^{2+}$ concentrations play an important role in cancer cell migration and tumor metastasis, and multiple $\mathrm{Ca}^{2+}$ channels have been linked to cancer cell migration. Inhibition of the TRPM7 channel resulted in reversal of epidermal growth factor (EGF)-induced migration of a lung cancer cell line and inhibited basal migration of the cells in the absence of EGF (Gao et al., 2011). High levels of TRPM7 expression predicted poor outcome in breast cancer patients and was functionally required for metastasis in a mouse xenograft model of human breast cancer (Middelbeek et al., 2012). Inhibition of TRPC6 activity showed reduced glioma cell growth, G2 phase cell cycle arrest, and reduced growth of subcutaneously and intracranially implanted gliomas, as well as increased survival of mice in vivo (Ding et al., 2010). Another study involving TRPC6 revealed that TRPC6 knockdown inhibited glioma cell invasion and angiogenesis, and they concluded that TRPC6 is required for development of the aggressive glioma phenotype (Chigurupati et al., 2010). Like NHE1 or NCKK, TRPC1 channels were localized to lipid raft domains at the leading edge of migrating glioma cells, and shRNA-mediated TRPC1 knockdown resulted in loss of EGF-induced glioma cell migration (Bomben et al., 2011).

\section{Ion Pumps}

The Na,K-ATPase has been linked to cancer cell motility and migration in vitro. Repletion of Na,K-ATPase $\beta_{1}$-subunit in Maloney Sarcoma virus transformed MDCK (MSV-MDCK) cells induced lamellipodia and suppressed motility in a phosphatidylinositol 3-kinase (PI3-kinase) dependent manner, and protein kinase $\mathrm{C}$ was involved upstream of PI3-kinase in the suppression of $\beta_{1}$-subunit mediated cell motility in carcinoma cells (Rajasekaran et al., 2001; Barwe et al., 
2005, 2006). The Na,K-ATPase $\alpha_{1}$-subunit associated with the regulatory subunit of $\mathrm{PI} 3$-kinase and $\beta_{1}$-subunit bound to anexin II, and these molecular interactions localized activated PI3-kinase at lamellipodia and suppressed cell motility in MSV-MDCK cells, independent of $\mathrm{Na}, \mathrm{K}$-ATPase ion transport activity (Barwe et al., 2005). Changes in Na,K-ATPase subunit expression were also found in various other cancers (Rajasekaran et al., 1999; Espineda et al., 2003; Lefranc et al., 2008; Mijatovic et al., 2008; Seligson et al., 2008; Rajasekaran and Rajasekaran, 2009). Ouabain, an Na,K-ATPase inhibitor, inhibited EGF induced medulloblastoma cell motility in a wound healing assay, prevented formation of EGF-induced actin stress fibers, and inhibited EGF-induced phospho-focal adhesion kinase (FAK) localization to the lamellipodia of medulloblastoma cells (Wolle et al., 2014). The Na,K-ATPase $\beta_{2}$-subunit has also been linked to cancer cell motility, specifically in glioblastoma multiforme. Na,K-ATPase $\beta_{2}$ subunit expression inhibits invasion of glioblastoma multiforme cells, and its downregulation increases invasion in glial cells (Sun et al., 2013). Another group found that inhibition or down regulation of Na,K-ATPase induced a cell death with characteristics of both apoptosis and necrosis, and disruption of $\mathrm{K}^{+}$homeostasis was important in induction of apoptosis in human glioblastoma cells (Chen et al., 2014).

\section{Ion Channels and Cell Signaling}

There is increasing evidence that ion channels can form signaling complexes with cell adhesion proteins including integrins. Integrins are a family of membrane-spanning glycoproteins that link ECM to the cytoskeleton. They are composed of $\alpha-\beta$ heterodimers with extracellular domains that bind ECM proteins and short cytoplasmic tails that associate with focal adhesion proteins. Integrins form signaling complexes at cell adhesion sites with other membrane receptors. Adaptor proteins such as Cas, Crk, and paxillin contribute to formation of adhesive complexes, which comprise focal adhesions. Downstream signaling pathways are then triggered by several enzymes including focal adhesion kinasse (FAK), the tyrosine kinase Src, and GTPases such as Ras and Rho (Brown, 2002). Evidence suggests that cellular processes that require activation of adhesion proteins such as cell differentiation, neurite extension and migration depend on ion channel activity. Multiple studies have demonstrated the crosstalk between ion channels and cell adhesion molecules. One of the first studies to reveal the formation of macromolecular complexes between integrins and ion channels came when McPhee et al. (1998) found that the $\mathrm{G}$ protein-gated inwardly rectifying $\mathrm{K}^{+}$channels (GIRKs) contain an Arginine-Glycine-Aspartate (RGD) sequence on their extracellular loop. RGD sequences mediate interaction between ECM proteins and integrins and are absent on the extracellular side of other $\mathrm{K}^{+}$channels. Further evidence showed that $\beta_{1}$ integrin associates with the $\mathrm{Na}, \mathrm{K}-\mathrm{ATP}$ ase and voltage gated $\mathrm{Ca}^{2+}$ channels (Shakibaei and Mobasheri, 2003). In PC12 cells, the shift to a neuronal phenotype induced by neural cell adhesion molecules and $\mathrm{N}$-cadherins is mediated by $\mathrm{Ca}^{2+}$ channels (Doherty et al., 1991). Integrins were observed to regulate neurite extension in neuroblastoma cells by activating $\mathrm{K}^{+}$channels (Arcangeli et al., 1993).

Ion pumps can also activate cellular signaling pathways. For example, in addition to its ion pumping function, Na,K-ATPase can also act as a signal transducer. When cells are exposed to drugs known to be specific inhibitors of Na,K-ATPase (such as ouabain, digoxin, and digitoxin), multiple intracellular signaling pathways are activated, including the Epidermal growth factor receptor (EGFR)/Src-Ras-Erk pathway and the PI3KPDK-Akt pathway (Pierre and Xie, 2006; Reinhard et al., 2013). Ouabain can activate the Ras and Erk signaling pathways. Src is necessary for ouabain-induced activation of the EGFR/RasErk pathway, and activation of PI3-kinase and Akt by ouabain leads to fibroblast cell proliferation (Wu et al., 2013). As mentioned earlier, the Na,K-ATPase $\beta_{1}$-subunit suppresses cell motility by cross talk between the two subunits of Na,K-ATPase with the PI3-kinase signaling pathway (Barwe et al., 2005). However, in medulloblastoma cells, ouabain did not transactivate EGFR as has been reported in other cell lines, and ouabain inhibited EGF-induced Erk1/2 and Akt activation (Wolle et al., 2014).

\section{Ion Channels, Proliferation and the Cell Cycle}

During development, tissues grow by proliferation, with some cell types able to divide throughout life. Cell proliferation is highly regulated in order to assure proper coordination of cell number. Cancer cells divide and proliferate faster than normal cells, resulting in tumor development. A role for ion channels in cell proliferation has been found in multiple cell types and cancers. Studies have found that some ion channel blockers also inhibit cell cycle progression and arrest cells at distinct stages of the cell cycle (Becchetti, 2011). For example, different potassium channels show cell-cycle-dependent variations in expression and activity (Pardo et al., 1998). Potassium channel blockers and depolarizing agents inhibit cell proliferation in oligodendrocyte progenitors in cell culture and cerebellar tissue slices by inducing G1 arrest through accumulation of p27 and p21, two cyclin dependent kinase (CDK) inhibitors involved in cell proliferation (Ghiani et al., 1999). Inhibition of the voltage gated $\mathrm{K}^{+}$channels $\mathrm{K}_{\mathrm{V}} 1.3$ and $\mathrm{K}_{\mathrm{V}} 1.5$ decreased proliferation of glioma cells (Pardo, 2004). For the $K_{V} 1.3$ channel, this affect on cell proliferation was due to interaction with the signaling adaptor protein 14-3-3 (Rajan et al., 2002). Also, inhibition of ATP-sensitive $\mathrm{K}^{+}$channels ( $\mathrm{K}_{\mathrm{ATP}}$ ) decreased proliferation in vitro and slowed tumor formation in xenografts, with cells arrested at G0/G1 phase of the cell cycle (Huang et al., 2009). Knockdown of Kir2.2 induced a significant increase in reactive oxygen species accompanied by cell cycle arrest. Moreover, pre-established tumors reduced in size after injection of siRNA targeting Kir2.2 (Lee et al., 2010). EAG channels are involved in cell cycle control, and inhibition of EAG expression in multiple cancer cell lines leads to reduction in cell proliferation (Pardo et al., 1999). Kir4.1 is also an important channel in regulating cell division (Turner and Sontheimer, 2014). Blocking the Kir4.1 channel in astrocytes induced proliferation, while overexpression in glioma cells arrested proliferation (Higashimori and Sontheimer, 2007). A role of BK channels in glioblastoma proliferation has been 
suggested (Chin et al., 1997; Wang, 2004). BK channel inhibition arrests glioma cells in S phase of the cell cycle, and causes a dose and time dependent decrease in cell number as early as $72 \mathrm{~h}$ after exposure (Weaver et al., 2004). Nevertheless, other groups suggested that some of the inhibitors of BK channels may regulate cell proliferation through off-target mechanisms (Abdullaev et al., 2010).

Calcium signaling also plays an important role in regulation of the cell cycle. Cells progressing from G1 to S require both extracellular calcium and functional membrane calcium channels in order to activate downstream signaling (Taylor et al., 2008). Partial inhibition of plasma membrane $\mathrm{Ca}^{2+}$ ATPase (PMCA) mediated calcium efflux reduced proliferation of MCF-7 breast cancer cells. An antisense construct directed towards PMCA lead to changes in cell cycle control kinetics, with a prolonged G2 phase that occurs with reduced $\mathrm{Ca}^{2+}$ efflux (Lee et al., 2005). Knockdown of TRPC6 expression inhibits glioma growth, invasion, and angiogenesis, and is an important mediator of glioblastoma tumor growth in vitro and in vivo (Chigurupati et al., 2010).

In addition, changes in sodium channels impact tumor cell proliferation. For example, the $\mathrm{nNa}_{\mathrm{V}} 1.5$ channel, a neonatal form of VGSC, was upregulated in human brain astrocytoma and positively correlated with the degree of malignancy while reduced $\mathrm{nNa}_{\mathrm{V}} 1.5$ expression significantly suppressed the proliferation of astrocytoma cells (Xing et al., 2014). Thus, modulation of various ion channels has profound effects on regulating cell cycle control and proliferation of cancer cells.

\section{Therapeutic Potential}

Most cancers are treated by surgical resection, chemotherapy, and radiation therapy. However due to the prevalence of cancer relapse with treatment resistance, novel molecular targets must be identified for the development of alternative therapies. Despite the growing evidence of aberrant expression and function of ion channels in oncology, development of cancer treatment using ion channel targeting compounds is still at an early stage. Studies have shown that some VGSC blockers can inhibit cell behaviors associated with metastasis. For example, the anticonvulsant phenytoin suppressed migration of prostate cancer cells (Fraser et al., 2003), and also inhibited migration and invasion in metastatic breast cancer cells (Yang et al., 2012). Riluzole, which is both a VGSC blocker and metabotropic glutamate receptor inhibitor, reduced the breast cancer tumor volume in mice, and suppressed metabolic activity of tumors in patients with stage III and IV melanoma (Yip et al., 2009). The $\mathrm{K}_{\mathrm{V}} 10.1$ EAG1 channel has been closely studied as a target for cancer therapy, since EAG1 overexpression is associated with tumorigenic potential, and its expression is correlated with poor patient survival in multiple cancer types (Pardo and Stühmer, 2008). The small molecule EAG1 blocker astemizole reduced EAG1-expressing cancer cell growth in vitro and in vivo (Downie et al., 2008). A highly specific extracellular epitope-targeting EAG1 monoclonal antibody exhibited antitumor activity in a mouse model (Gómez-Varela et al., 2007). T-type $\mathrm{Ca}^{2+}$ channels have also been suggested as a potential therapeutic target for certain brain tumors. Mibefradil, a calcium channel inhibitor, was found to inhibit proliferation in human glioma and neuroblastoma cells, and overexpression of T-type $\mathrm{Ca}^{2+}$ channel protein doubled the proliferation rate while antisense treatment reduced the proliferation rate of these cells (Panner et al., 2005). The Na,K-ATPase is another potential target for cancer therapy. Human glioblastoma cells that are resistant to the chemotherapy drug temozolomide (TMZ) show a higher expression of Na,K-ATPase $\alpha_{2}$ - and $\alpha_{3}$ subunits compared to TMZ-sensitive cells and astrocytes. These cells were also sensitive to ouabain at low concentrations, and knockdown of the $\alpha_{3}$-subunit sensitized the cells to TMZ (Chen et al., 2014). Judging from the large number of ion channels that are altered in cancers, it is clear that understanding more about ion channels and pumps and how they contribute to cancer progression could reveal new therapeutic targets for many different cancers. The findings discussed above provide proof of principle that ion channels are effective targets for cancer therapy.

\section{Conclusions}

Increasing evidence suggests that ion channels and pumps are involved in the regulation of cell proliferation and migration, and channel proteins have been shown to form macromolecular complexes with cell adhesion molecules and other signaling proteins. As these roles of ion channels and pumps are further elucidated, it is being increasingly suggested that regulation of ion channels and pumps could contribute to cancer progression. Here we discussed that aberrant expression and function of several types of ion channels and pumps have been found in multiple cancers including brain cancer, and in particular, glioblastoma. Knowing that these proteins are involved in multiple malignant characteristics of multiple cancers, ion channels and pumps could be potential targets for therapy.

\section{Acknowledgments}

Support was provided by the National Institute of General Medical Sciences of the National Institutes of Health Awards Number NIGMS-P20GM103464, the American Cancer Society Grant Number RSG-09-021-01-CNE, the DO Believe Foundation, and The Nemours Foundation.

\section{Abbreviations}

ASIC, Acid-sensing ion channel; BK, Big conductance channel; CDK, Cyclin dependent kinase; CFTR, Cystic fibrosis transmembrane conductance regulator; EAG1, Voltage gated eag related subfamily $\mathrm{H}$, member 1; ECM, Extracellular matrix; EGF, Epidermal growth factor; EGFR, Epidermal growth factor receptor; ER, Endoplasmic reticulum; FAK, Focal adhesion kinase; GIRK, G protein-gated inwardly rectifying $\mathrm{K}^{+}$channel; HER2, Human epidermal growth factor receptor 2; IK, Intermediate conductance channel; K2P, Two-pore domain potassium channel; $\mathrm{K}_{\mathrm{ATP}}$, ATP-sensitive $\mathrm{K}^{+}$channels; $\mathrm{KCa}$, Calcium-activated potassium channel; Kir, Inward 
rectifying potassium channel; KV, Voltage-gated potassium channel; MDCK-F, transformed Madin-Darby canine kidney; $\mathrm{Na}, \mathrm{K}-\mathrm{ATPase}$, Sodium potassium ATPase; NHE1, $\mathrm{Na}^{+} / \mathrm{H}^{+}$ exchanger; $\mathrm{NKCC}, \mathrm{Na}^{+}, \mathrm{K}^{+}, 2 \mathrm{Cl}^{-}$cotransporter; PI3-kinase, Phosphatidylinositol 3-kinase; PMCA, Plasma Membrane

\section{References}

Abdullaev, I. F., Rudkouskaya, A., Mongin, A. A., and Kuo, Y. H. (2010). Calcium-activated potassium channels BK and IK1 are functionally expressed in human gliomas but do not regulate cell proliferation. PLoS One 5:e12304. doi: 10.1371/journal.pone.0012304

Alevizopoulos, K., Calogeropoulou, T., Lang, F., and Stournaras, C. (2014). $\mathrm{Na}^{+} / \mathrm{K}^{+}$ATPase inhibitors in cancer. Curr. Drug Targets 15, 988-1000. doi: 10. 2174/1389450115666140908125025

Amith, S. R., and Fliegel, L. (2013). Regulation of the $\mathrm{Na}^{+} / \mathrm{H}^{+}$Exchanger (NHE1) in Breast Cancer metastasis. Cancer Res. 73, 1259-1264. doi: 10.1158/00085472.CAN-12-4031

Arcangeli, A., Becchetti, A., Mannini, A., Mugnai, G., De Filippi, P., Tarone, G., et al. (1993). Integrin-mediated neurite outgrowth in neuroblastoma cells depends on the activation of potassium channels. J. Cell Biol. 122, 1131-1143. doi: $10.1083 /$ jcb.122.5.1131

Aydar, E., Yeo, S., Djamgoz, M., and Palmer, C. (2009). Abnormal expression, localization and interaction of canonical transient receptor potential ion channels in human breast cancer cell lines and tissues: a potential target for breast cancer diagnosis and therapy. Cancer Cell Int. 9:23. doi: 10.1186/14752867-9-23

Barwe, S. P., Anilkumar, G., Moon, S. Y., Zheng, Y., Whitelegge, J. P., Rajasekaran, S. A., et al. (2005). Novel role for Na,K-ATPase in phosphatidylinositol 3-kinase signaling and suppression of cell motility. Mol. Biol. Cell 16, 1082-1094. doi: 10. 1091/mbc.e04-05-0427

Barwe, S. P., Rajasekaran, S. A., and Rajasekaran, A. K. (2006). Identification of protein kinase $\mathrm{C}$ as an intermediate in Na,K-ATPase beta-subunit mediated lamellipodia formation and suppression of cell motility in carcinoma cells. Cell. Mol. Biol. (Noisy-le-grand) 52, 41-47.

Becchetti, A. (2011). Ion channels and transporters in cancer. 1. Ion channels and cell proliferation in cancer. Am. J. Physiol. Cell Physiol. 301, C255-C265. doi: 10.1152/ajpcell.00047.2011

Bennett, E. S., Smith, B. A., and Harper, J. M. (2004). Voltage-gated Na ${ }^{+}$channels confer invasive properties on human prostate cancer cells. Pflugers Arch. 447, 908-914. doi: 10.1007/s00424-003-1205-x

Bomben, V. C., Turner, K. L., Barclay, T. T., and Sontheimer, H. (2011). Transient receptor potential canonical channels are essential for chemotactic migration of human malignant gliomas. J. Cell Physiol. 226, 1879-1888. doi: 10.1002/ jcp. 22518

Brackenbury, W. J. (2012). Voltage-gated sodium channels and metastatic disease. Channels (Austin) 6, 352-361. doi: 10.4161/chan.21910

Brackenbury, W. J., Davis, T. H., Chen, C., Slat, E. A., Detrow, M. J., Dickendesher, T. L., et al. (2008). Voltage-gated $\mathrm{Na}^{+}$channel betal subunit-mediated neurite outgrowth requires Fyn kinase and contributes to postnatal CNS development in vivo. J. Neurosci. 28, 3246-3256. doi: 10.1523/JNEUROSCI.5446-07.2008

Brisson, L., Driffort, V., Benoist, L., Poet, M., Counillon, L., Antelmi, E., et al. (2013). Nav1.5 $\mathrm{Na}^{+}$channels allosterically regulate the NHE-1 exchanger and promote the activity of breast cancer cell invadopodia. J. Cell Sci. 126, 4835-4842. doi: 10.1242/jcs. 123901

Brown, E. J. (2002). Integrin-associated proteins. Curr. Opin. Cell Biol. 14, 603-607. doi: 10.1016/s0955-0674(02)00360-5

Bustin, S. A., Li, S. R., and Dorudi, S. (2001). Expression of the $\mathrm{Ca}^{2+}$. activated chloride channel genes CLCA1 and CLCA2 is downregulated in human colorectal cancer. DNA Cell Biol. 20, 331-338. doi: 10.1089/ 10445490152122442

Camerino, D. C., Tricarico, D., and Desaphy, J. F. (2007). Ion channel pharmacology. Neurotherapeutics 4, 184-198. doi: 10.1016/j.nurt.2007.01.013

Cardone, R. A., Casavola, V., and Reshkin, S. J. (2005). The role of disturbed $\mathrm{pH}$ dynamics and the $\mathrm{Na}^{+} / \mathrm{H}^{+}$exchanger in metastasis. Nat. Rev. Cancer 5, 786-795 doi: $10.1038 / \mathrm{nrc1713}$
$\mathrm{Ca}^{2+}$ ATPase; RGD, Arginine-Glycine-Aspartate; SERCA, Sarcoplasmic and endoplasmic reticulum Ca-ATPase; SK, Small conductance channel; TMZ, Temozolomide; TRP, Transient receptor potential channel; VEGFR, Vascular endothelial growth factor receptor; VGSC, Voltage gated sodium channel.

Catacuzzeno, L., Aiello, F., Fioretti, B., Sforna, L., Castigli, E., Ruggieri, P., et al. (2011). Serum-activated $\mathrm{K}$ and $\mathrm{Cl}$ currents underlay U87-MG glioblastoma cell migration. J. Cell. Physiol. 226, 1926-1933. doi: 10.1002/jcp.22523

Catacuzzeno, L., Fioretti, B., and Franciolini, F. (2012). Expression and role of the intermediate-conductance calcium-activated Potassium channel KCa3.1 in Glioblastoma. J. Signal Transduct. 2012:421564. doi: 10.1155/2012/421564

Chambers, A. F., Groom, A. C., and MacDonald, I. C. (2002). Metastasis: dissemination and growth of cancer cells in metastatic sites. Nat. Rev. Cancer 2, 563-572. doi: 10.1038/nrc865

Chantôme, A., Potier-Cartereau, M., Clarysse, L., Fromont, G., MarionneauLambot, S., Gueguinou, M., et al. (2013). Pivotal role of the lipid Raft SK3-Orai1 complex in human cancer cell migration and bone metastases. Cancer Res. 73, 4852-4861. doi: 10.1158/0008-5472.CAN-12-4572

Chen, Y. F., Chen, Y. T., Chiu, W. T., and Shen, M. R. (2013). Remodeling of calcium signaling in tumor progression. J. Biomed Sci. 20:23. doi: 10.1186/14230127-20-23

Chen, D., Song, M., Mohamad, O., and Yu, S. P. (2014). Inhibition of $\mathrm{Na}^{+} / \mathrm{K}^{+}$. ATPase induces hybrid cell death and enhanced sensitivity to chemotherapy in human glioblastoma cells. BMC Cancer 14:716. doi: 10.1186/1471-2407-14-716

Cherubini, A., Hofmann, G., Pillozzi, S., Guasti, L., Crociani, O., Cilia, E., et al. (2005). Human ether-a-go-go-related gene 1 channels are physically linked to betal integrins and modulate adhesion-dependent signaling. Mol. Biol. Cell 16, 2972-2983. doi: 10.1091/mbc.e04-10-0940

Chigurupati, S., Venkataraman, R., Barrera, D., Naganathan, A., Madan, M., Paul, L., et al. (2010). Receptor channel TRPC6 is a key mediator of Notchdriven glioblastoma growth and invasiveness. Cancer Res. 70, 418-427. doi: 10. 1158/0008-5472.CAN-09-2654

Chin, L. S., Park, C. C., Zitnay, K. M., Sinha, M., DiPatri, A. J. Jr., Perillán, P., et al. (1997). 4-Aminopyridine causes apoptosis and blocks an outward rectifier $\mathrm{K}^{+}$channel in malignant astrocytoma cell lines. J. Neurosci. Res. 48, 122-127. doi: 10.1002/(sici)1097-4547(19970415)48:2<122::aid-jnr4>3.0.co;2-e

Chioni, A. M., Brackenbury, W. J., Calhoun, J. D., Isom, L. L., and Djamgoz, M. B. (2009). A novel adhesion molecule in human breast cancer cells: voltage-gated $\mathrm{Na}^{+}$channel betal subunit. Int. J. Biochem. Cell Biol. 41, 1216-1227. doi: 10. 1016/j.biocel.2008.11.001

Chioni, A. M., Shao, D., Grose, R., and Djamgoz, M. B. (2010). Protein kinase A and regulation of neonatal $\mathrm{Na}_{\mathrm{V}} 1.5$ expression in human breast cancer cells: activity-dependent positive feedback and cellular migration. Int. J. Biochem. Cell Biol. 42, 346-358. doi: 10.1016/j.biocel.2009.11.021

Comes, N., Bielanska, J., Vallejo-Gracia, A., Serrano-Albarrás, A., Marruecos, L., Gómez, D., et al. (2013). The voltage-dependent $\mathrm{K}^{(+)}$channels $\mathrm{K}_{\mathrm{V}} 1.3$ and KV1.5 in human cancer. Front. Physiol. 4:283. doi: 10.3389/fphys.2013.00283

Comes, N., Serrano-Albarrás, A., Capera, J., Serrano-Novillo, C., Condom, E., Ramón, Y. C. S., et al. (2014). Involvement of potassium channels in the progression of cancer to a more malignant phenotype. Biochim. Biophys. Acta doi: 10.1016/j.bbamem.2014.12.008. [Epub ahead of print].

Cuddapah, V. A., and Sontheimer, H. (2010). Molecular interaction and functional regulation of ClC-3 by $\mathrm{Ca}^{2+} /$ calmodulin-dependent protein kinase II (CaMKII) in human malignant glioma. J. Biol. Chem. 285, 11188-11196. doi: 10.1074/jbc.M109.097675

Cuddapah, V. A., Turner, K. L., Seifert, S., and Sontheimer, H. (2013). Bradykinininduced chemotaxis of human gliomas requires the activation of KCa3.1 and ClC-3. J. Neurosci. 33, 1427-1440. doi: 10.1523/JNEUROSCI.3980-12.2013

Davis, T. H., Chen, C., and Isom, L. L. (2004). Sodium channel beta1 subunits promote neurite outgrowth in cerebellar granule neurons. J. Biol. Chem. 279, 51424-51432. doi: 10.1074/jbc.m410830200

deHart, G. W., Jin, T., McCloskey, D. E., Pegg, A. E., and Sheppard, D. (2008). The $\alpha 9 \beta 1$ integrin enhances cell migration by polyamine-mediated modulation of an inward-rectifier potassium channel. Proc. Natl. Acad. Sci. U S A 105, 7188-7193. doi: 10.1073/pnas.0708044105 
Denmeade, S. R., Jakobsen, C. M., Janssen, S., Khan, S. R., Garrett, E. S., Lilja, H., et al. (2003). Prostate-specific antigen-activated thapsigargin prodrug as targeted therapy for prostate cancer. J. Natl. Cancer Inst. 95, 990-1000. doi: 10. 1093/jnci/95.13.990

Ding, X., He, Z., Zhou, K., Cheng, J., Yao, H., Lu, D., et al. (2010). Essential role of TRPC6 channels in G2/M phase transition and development of human glioma. J. Natl. Cancer Inst. 102, 1052-1068. doi: 10.1093/jnci/djq217

Djamgoz, M. B. A., Coombes, R. C., and Schwab, A. (2014). Ion transport and cancer: from initiation to metastasis. Philos. Trans. R. Soc. Lond. B Biol. Sci. 369:20130092. doi: 10.1098/rstb.2013.0092

Doherty, P., Ashton, S. V., Moore, S. E., and Walsh, F. S. (1991). Morphoregulatory activities of NCAM and N-cadherin can be accounted for by G proteindependent activation of L- and N-type neuronal $\mathrm{Ca}^{2+}$ channels. Cell 67, 21-33. doi: 10.1016/0092-8674(91)90569-k

Downie, B. R., Sánchez, A., Knötgen, H., Contreras-Jurado, C., Gymnopoulos, M., Weber, C., et al. (2008). Eag1 expression interferes with hypoxia homeostasis and induces angiogenesis in tumors. J. Biol. Chem. 283, 36234-36240. doi: 10. 1074/jbc.M801830200

Driffort, V., Gillet, L., Bon, E., Marionneau-Lambot, S., Oullier, T., Joulin, V., et al. (2014). Ranolazine inhibits $\mathrm{Na}_{V} 1.5$-mediated breast cancer cell invasiveness and lung colonization. Mol. Cancer 13:264. doi: 10.1186/1476-4598-13-264

Espineda, C. E., Chang, J. H., Twiss, J., Rajasekaran, S. A., and Rajasekaran, A. K. (2004). Repression of Na,K-ATPase betal-subunit by the transcription factor snail in carcinoma. Mol. Biol. Cell 15, 1364-1373. doi: 10.1091/mbc.e0309-0646

Espineda, C., Seligson, D. B., James Ball, W. Jr., Rao, J., Palotie, A., Horvath, S., et al. (2003). Analysis of the Na,K-ATPase alpha- and beta-subunit expression profiles of bladder cancer using tissue microarrays. Cancer 97, 1859-1868. doi: $10.1002 /$ cncr.11267

Fraser, S. P., Ozerlat-Gunduz, I., Brackenbury, W. J., Fitzgerald, E. M., Campbell, T. M., Coombes, R. C., et al. (2014). Regulation of voltage-gated sodium channel expression in cancer: hormones, growth factors and auto-regulation. Philos. Trans. R. Soc. Lond. B Biol. Sci. 369:20130105. doi: 10.1098/rstb. 2013.0105

Fraser, S. P., Salvador, V., Manning, E. A., Mizal, J., Altun, S., Raza, M., et al. (2003). Contribution of functional voltage-gated $\mathrm{Na}^{+}$channel expression to cell behaviors involved in the metastatic cascade in rat prostate cancer: I. Lateral motility. J. Cell. Physiol. 195, 479-487. doi: 10.1002/jcp.10312

Friedl, P., and Alexander, S. (2011). Cancer invasion and the microenvironment: plasticity and reciprocity. Cell 147, 992-1009. doi: 10.1016/j.cell.2011. 11.016

Gadsby, D. C. (2009). Ion channels versus ion pumps: the principal difference, in principle. Nat. Rev. Mol. Cell Biol. 10, 344-352. doi: 10.1038/nrm2668

Gao, H., Chen, X., Du, X., Guan, B., Liu, Y., and Zhang, H. (2011). EGF enhances the migration of cancer cells by up-regulation of TRPM7. Cell Calcium 50, 559-568. doi: 10.1016/j.ceca.2011.09.003

Garzon-Muvdi, T., Schiapparelli, P., ap Rhys, C., Guerrero-Cazares, H., Smith, C., Kim, D. H., et al. (2012). Regulation of brain tumor dispersal by NKCC1 through a novel role in focal adhesion regulation. PLoS Biol. 10:e1001320. doi: 10.1371/journal.pbio.1001320

Ghiani, C. A., Yuan, X., Eisen, A. M., Knutson, P. L., DePinho, R. A., McBain, C. J., et al. (1999). Voltage-activated $\mathrm{K}^{+}$channels and membrane depolarization regulate accumulation of the cyclin-dependent kinase inhibitors p27(Kip1) and p21(CIP1) in glial progenitor cells. J. Neurosci. 19, 5380-5392.

Gómez-Varela, D., Zwick-Wallasch, E., Knötgen, H., Sánchez, A., Hettmann, T., Ossipov, D., et al. (2007). Monoclonal antibody blockade of the human Eag1 potassium channel function exerts antitumor activity. Cancer Res. 67, 7343-7349. doi: 10.1158/0008-5472.can-07-0107

Gorbatenko, A., Olesen, C. W., Mørup, N., Thiel, G., Kallunki, T., Valen, E., et al. (2014). ErbB2 upregulates the $\mathrm{Na}^{+}, \mathrm{HCO}_{3}(-)$-cotransporter $\mathrm{NBCn} 1 / \mathrm{SLC} 4 \mathrm{~A} 7$ in human breast cancer cells via Akt, ERK, Src and Kruppel-like factor 4. FASEB J. 28, 350-363. doi: 10.1096/fj.13-233288

Grimes, J. A., Fraser, S. P., Stephens, G. J., Downing, J. E., Laniado, M. E., Foster, C. S., et al. (1995). Differential expression of voltage-activated $\mathrm{Na}^{+}$currents in two prostatic tumour cell lines: contribution to invasiveness in vitro. FEBS Lett. 369, 290-294. doi: 10.1016/0014-5793(95)00772-2

Haas, B. R., and Sontheimer, H. (2010). Inhibition of the Sodium-PotassiumChloride Cotransporter Isoform-1 reduces glioma invasion. Cancer Res. 70, 5597-5606. doi: 10.1158/0008-5472.CAN-09-4666
Hatten, M. E., and Roussel, M. F. (2011). Development and cancer of the cerebellum. Trends Neurosci. 34, 134-142. doi: 10.1016/j.tins.2011.01.002

Higashimori, H., and Sontheimer, H. (2007). Role of Kir4.1 channels in growth control of glia. Glia 55, 1668-1679. doi: 10.1002/glia.20574

Huang, X., and Jan, L. Y. (2014). Targeting potassium channels in cancer. J. Cell Biol. 206, 151-162. doi: 10.1083/jcb.201404136

Huang, L., Li, B., Li, W., Guo, H., and Zou, F. (2009). ATP-sensitive potassium channels control glioma cells proliferation by regulating ERK activity. Carcinogenesis 30, 737-744. doi: 10.1093/carcin/bgp034

Ismailov, I. I., and Benos, D. J. (1995). Effects of phosphorylation on ion channel function. Kidney Int. 48, 1167-1179. doi: 10.1038/ki.1995.400

Jansson, K. H., Lynch, J. E., Lepori-Bui, N., Czymmek, K. J., Duncan, R. L., and Sikes, R. A. (2012). Overexpression of the VSSC-associated CAM, beta-2, enhances LNCaP cell metastasis associated behavior. Prostate 72, 1080-1092. doi: $10.1002 /$ pros.21512

Joshi, A. D., Parsons, D. W., Velculescu, V. E., and Riggins, G. J. (2011). Sodium ion channel mutations in glioblastoma patients correlate with shorter survival. Mol. Cancer 10:17. doi: 10.1186/1476-4598-10-17

Kapoor, N., Bartoszewski, R., Qadri, Y. J., Bebok, Z., Bubien, J. K., Fuller, C. M., et al. (2009). Knockdown of ASIC1 and epithelial sodium channel subunits inhibits glioblastoma whole cell current and cell migration. J. Biol. Chem. 284, 24526-24541. doi: 10.1074/jbc.M109.037390

Kraft, R., Krause, P., Jung, S., Basrai, D., Liebmann, L., Bolz, J., et al. (2003). BK channel openers inhibit migration of human glioma cells. Pflugers Arch. 446, 248-255.

Laniado, M. E., Lalani, E. N., Fraser, S. P., Grimes, J. A., Bhangal, G., Djamgoz, M. B., et al. (1997). Expression and functional analysis of voltage-activated $\mathrm{Na}^{+}$ channels in human prostate cancer cell lines and their contribution to invasion in vitro. Am. J. Pathol. 150, 1213-1221.

Lee, I., Park, C., and Kang, W. K. (2010). Knockdown of inwardly rectifying potassium channel Kir2.2 suppresses tumorigenesis by inducing reactive oxygen species-mediated cellular senescence. Mol. Cancer Ther. 9, 2951-2959. doi: 10.1158/1535-7163.MCT-10-0511

Lee, W. J., Robinson, J. A., Holman, N. A., McCall, M. N., Roberts-Thomson, S. J., and Monteith, G. R. (2005). Antisense-mediated inhibition of the plasma membrane calcium-ATPase suppresses proliferation of MCF-7 cells. J. Biol. Chem. 280, 27076-27084. doi: 10.1074/jbc.m414142200

Lefranc, F., Mijatovic, T., Kondo, Y., Sauvage, S., Roland, I., Debeir, O., et al. (2008). Targeting the alpha 1 subunit of the sodium pump to combat glioblastoma cells. Neurosurgery 62, 211-221; discussion 221-222. doi: 10 . 1227/01.NEU.0000311080.43024.0E

Liu, X., Chang, Y., Reinhart, P. H., Sontheimer, H., and Chang, Y. (2002). Cloning and characterization of glioma BK, a novel BK channel isoform highly expressed in human glioma cells. J. Neurosci. 22, 1840-1849.

Liu, H., Li, Y., and Raisch, K. P. (2010). Clotrimazole induces a late G1 cell cycle arrest and sensitizes glioblastoma cells to radiation in vitro. Anticancer Drugs 21, 841-849. doi: 10.1097/CAD.0b013e32833e8022

McPhee, J. C., Dang, Y. L., Davidson, N., and Lester, H. A. (1998). Evidence for a functional interaction between integrins and $G$ protein-activated inward rectifier K ${ }^{+}$channels. J. Biol. Chem. 273, 34696-34702. doi: 10.1074/jbc.273.52. 34696

Menger, L., Vacchelli, E., Adjemian, S., Martins, I., Ma, Y., Shen, S., et al. (2012). Cardiac glycosides exert anticancer effects by inducing immunogenic cell death. Sci. Transl. Med. 4:143ra199. doi: 10.1126/scitranslmed. 3003807

Middelbeek, J., Kuipers, A. J., Henneman, L., Visser, D., Eidhof, I., van Horssen, R., et al. (2012). TRPM7 is required for breast tumor cell metastasis. Cancer Res. 72, 4250-4261. doi: 10.1158/0008-5472.can-11-3863

Mijatovic, T., Ingrassia, L., Facchini, V., and Kiss, R. (2008). $\mathrm{Na}^{+} / \mathrm{K}^{+}$-ATPase alpha subunits as new targets in anticancer therapy. Expert Opin. Ther. Targets 12, 1403-1417. doi: 10.1517/14728222.12.11.1403

Newman, R. A., Yang, P., Pawlus, A. D., and Block, K. I. (2008). Cardiac glycosides as novel cancer therapeutic agents. Mol. Interv. 8, 36-49. doi: 10.1124/ mi.8.1.8

Northcott, P. A., Dubuc, A. M., Pfister, S., and Taylor, M. D. (2012). Molecular subgroups of medulloblastoma. Expert Rev. Neurother. 12, 871-884. doi: 10. 1586/ern. 12.66

Overington, J. P., Al-Lazikani, B., and Hopkins, A. L. (2006). How many drug targets are there? Nat. Rev. Drug Discov. 5, 993-996. doi: 10.1038/nrd2199 
Panner, A., Cribbs, L. L., Zainelli, G. M., Origitano, T. C., Singh, S., and Wurster, R. D. (2005). Variation of T-type calcium channel protein expression affects cell division of cultured tumor cells. Cell Calcium 37, 105-119. doi: 10.1016/j.ceca. 2004.07.002

Pardo, L. A. (2004). Voltage-gated potassium channels in cell proliferation. Physiology (Bethesda) 19, 285-292. doi: 10.1152/physiol.00011.2004

Pardo, L. A., Brüggemann, A., Camacho, J., and Stühmer, W. (1998). Cell cyclerelated changes in the conducting properties of r-eag $\mathrm{K}^{+}$channels. J. Cell Biol. 143, 767-775. doi: 10.1083/jcb.143.3.767

Pardo, L. A., del Camino, D., Sánchez, A., Alves, F., Brüggemann, A., Beckh, S., et al. (1999). Oncogenic potential of EAG $\mathrm{K}^{(+)}$channels. EMBO J. 18, 5540-5547. doi: 10.1093/emboj/18.20.5540

Pardo, L. A., and Stühmer, W. (2008). Eag1: an emerging oncological target. Cancer Res. 68, 1611-1613. doi: 10.1158/0008-5472.CAN-07-5710

Patt, S., Preussat, K., Beetz, C., Kraft, R., Schrey, M., Kalff, R., et al. (2004). Expression of ether a go-go potassium channels in human gliomas. Neurosci. Lett. 368, 249-253. doi: 10.1016/j.neulet.2004.07.001

Pedersen, S. F., and Stock, C. (2013). Ion channels and transporters in cancer: pathophysiology, regulation and clinical potential. Cancer Res. 73, 1658-1661. doi: 10.1158/0008-5472.CAN-12-4188

Pierre, S. V., and Xie, Z. (2006). The Na,K-ATPase receptor complex: its organization and membership. Cell Biochem. Biophys. 46, 303-316. doi: 10. 1385/cbb:46:3:303

Pillozzi, S., Brizzi, M. F., Balzi, M., Crociani, O., Cherubini, A., Guasti, L., et al. (2002). HERG potassium channels are constitutively expressed in primary human acute myeloid leukemias and regulate cell proliferation of normal and leukemic hemopoietic progenitors. Leukemia 16, 1791-1798. doi: 10.1038/sj. leu. 2402572

Prassas, I., and Diamandis, E. P. (2008). Novel therapeutic applications of cardiac glycosides. Nat. Rev. Drug Discov. 7, 926-935. doi: 10.1038/nrd2682

Rajan, S., Preisig-Müller, R., Wischmeyer, E., Nehring, R., Hanley, P. J., Renigunta, V., et al. (2002). Interaction with 14-3-3 proteins promotes functional expression of the potassium channels TASK-1 and TASK-3. J. Physiol. 545, 13-26. doi: 10.1113/jphysiol.2002.027052

Rajasekaran, S. A., Ball, W. J. Jr., Bander, N. H., Liu, H., Pardee, J. D., and Rajasekaran, A. K. (1999). Reduced expression of beta-subunit of Na,K-ATPase in human clear-cell renal cell carcinoma. J. Urol. 162, 574-580. doi: 10. 1097/00005392-199908000-00089

Rajasekaran, S. A., Palmer, L. G., Quan, K., Harper, J. F., Ball, W. J. Jr., Bander, N. H., et al. (2001). Na,K-ATPase beta-subunit is required for epithelial polarization, suppression of invasion and cell motility. Mol. Biol. Cell 12, 279-295. doi: 10.1091/mbc.12.2.279

Rajasekaran, S. A., and Rajasekaran, A. K. (2009). Na,K-ATPase and epithelial tight junctions. Front. Biosci. (Landmark Ed.) 14, 2130-2148. doi: 10.2741/3367

Reinhard, L., Tidow, H., Clausen, M. J., and Nissen, P. (2013). $\mathrm{Na}^{+}, \mathrm{K}^{+}$-ATPase as a docking station: protein-protein complexes of the $\mathrm{Na}^{+}, \mathrm{K}^{+}$-ATPase. Cell Mol. Life Sci. 70, 205-222. doi: 10.1007/s00018-012-1039-9

Roti, G., Carlton, A., Ross, K. N., Markstein, M., Pajcini, K., Su, A. H., et al. (2013). Complementary genomic screens identify SERCA as a therapeutic target in NOTCH1 mutated cancer. Cancer Cell 23, 390-405. doi: 10.1016/j.ccr.2013. 01.015

Schrey, M., Codina, C., Kraft, R., Beetz, C., Kalff, R., Wölfl, S., et al. (2002). Molecular characterization of voltage-gated sodium channels in human gliomas. Neuroreport 13, 2493-2498. doi: 10.1097/00001756-200212200-00023

Schwab, A., Fabian, A., Hanley, P. J., and Stock, C. (2012). Role of ion channels and transporters in cell migration. Physiol. Rev. 92, 1865-1913. doi: 10. $1152 /$ physrev.00018.2011

Schwab, A., Schuricht, B., Seeger, P., Reinhardt, J., and Dartsch, P. C. (1999). Migration of transformed renal epithelial cells is regulated by $\mathrm{K}^{+}$channel modulation of actin cytoskeleton and cell volume. Pflugers Arch. 438, 330-337. doi: $10.1007 /$ s004240050917

Schwab, A., and Stock, C. (2014). Ion channels and transporters in tumour cell migration and invasion. Philos. Trans. R. Soc. Lond. B Biol. Sci. 369:20130102. doi: $10.1098 / \mathrm{rstb} .2013 .0102$

Schwartz, M. A., and Horwitz, A. R. (2006). Integrating adhesion, protrusion and contraction during cell migration. Cell 125, 1223-1225. doi: 10.1016/j.cell.2006. 06.015

Sciaccaluga, M., Fioretti, B., Catacuzzeno, L., Pagani, F., Bertollini, C., Rosito, M., et al. (2010). CXCL12-induced glioblastoma cell migration requires intermediate conductance $\mathrm{Ca}^{2+}$-activated $\mathrm{K}^{+}$channel activity. Am. J. Physiol. Cell Physiol. 299, C175-C184. doi: 10.1152/ajpcell.00344.2009

Seligson, D. B., Rajasekaran, S. A., Yu, H., Liu, X., Eeva, M., Tze, S., et al. (2008). $\mathrm{Na}, \mathrm{K}$-adenosine triphosphatase alpha1-subunit predicts survival of renal clear cell carcinoma. J. Urol. 179, 338-345. doi: 10.1016/j.juro.2007.08.094

Shakibaei, M., and Mobasheri, A. (2003). Betal-integrins co-localize with $\mathrm{Na}$, K-ATPase, epithelial sodium channels $(\mathrm{ENaC})$ and voltage activated calcium channels (VACC) in mechanoreceptor complexes of mouse limb-bud chondrocytes. Histol. Histopathol. 18, 343-351.

Shan, B., Dong, M., Tang, H., Wang, N., Zhang, J., Yan, C., et al. (2014). Voltagegated sodium channels were differentially expressed in human normal prostate, benign prostatic hyperplasia and prostate cancer cells. Oncol. Lett. 8, 345-350. doi: $10.3892 / \mathrm{ol} .2014 .2110$

Sontheimer, H. (2004). Ion channels and amino acid transporters support the growth and invasion of primary brain tumors. Mol. Neurobiol. 29, 61-71. doi: $10.1385 / \mathrm{mn}: 29: 1: 61$

Sontheimer, H. (2008). An unexpected role for ion channels in brain tumor metastasis. Exp. Biol. Med. (Maywood) 233, 779-791. doi: 10.3181/ 0711-mr-308

Soroceanu, L., Manning, T. J. Jr., and Sontheimer, H. (1999). Modulation of glioma cell migration and invasion using $\mathrm{Cl}^{(-)}$and $\mathrm{K}^{(+)}$ion channel blockers. $J$. Neurosci. 19, 5942-5954.

Stock, C., Ludwig, F. T., and Schwab, A. (2012). Is the multifunctional $\mathrm{Na}^{(+)} / \mathrm{H}^{(+)}$ exchanger isoform 1 a potential therapeutic target in cancer? Curr. Med. Chem. 19, 647-660. doi: 10.2174/092986712798992101

Stroka, K. M., Jiang, H., Chen, S. H., Tong, Z., Wirtz, D., Sun, S. X., et al. (2014). Water permeation drives tumor cell migration in confined microenvironments. Cell 157, 611-623. doi: 10.1016/j.cell.2014.02.052

Stüwe, L., Müller, M., Fabian, A., Waning, J., Mally, S., Noël, J., et al. (2007). pH dependence of melanoma cell migration: protons extruded by NHE1 dominate protons of the bulk solution. J. Physiol. 585, 351-360. doi: 10.1113/jphysiol. 2007.145185

Sun, M. Z., Kim, J. M., Oh, M. C., Safaee, M., Kaur, G., Clark, A. J., et al. (2013). $\mathrm{Na}(+) / \mathrm{K}(+)$-ATPase beta2-subunit (AMOG) expression abrogates invasion of glioblastoma-derived brain tumor-initiating cells. Neuro Oncol. 15, 1518-1531. doi: 10.1093/neuonc/not099

Taylor, J. T., Zeng, X. B., Pottle, J. E., Lee, K., Wang, A. R., Yi, S. G., et al. (2008). Calcium signaling and T-type calcium channels in cancer cell cycling. World J. Gastroenterol. 14, 4984-4991. doi: 10.3748/wjg.14.4984

Turner, K. L., and Sontheimer, H. (2014). $\mathrm{Cl}^{-}$and $\mathrm{K}^{+}$channels and their role in primary brain tumour biology. Philos. Trans. R. Soc. Lond. B Biol. Sci. 369:20130095. doi: 10.1098/rstb.2013.0095

Ullrich, N., and Sontheimer, H. (1997). Cell cycle-dependent expression of a glioma-specific chloride current: proposed link to cytoskeletal changes. Am. J. Physiol. 273, C1290-C1297.

Vahle, A. K., Domikowsky, B., Schwöppe, C., Krähling, H., Mally, S., Schäfers, M., et al. (2014). Extracellular matrix composition and interstitial $\mathrm{pH}$ modulate NHE1-mediated melanoma cell motility. Int. J. Oncol. 44, 78-90. doi: 10 3892/ijo.2013.2158

Wang, Z. (2004). Roles of $\mathrm{K}^{+}$channels in regulating tumour cell proliferation and apoptosis. Pflügers Arch. 448, 274-286. doi: 10.1007/s00424-0041258-5

Watkins, S., and Sontheimer, H. (2011). Hydrodynamic cellular volume changes enable glioma cell invasion. J. Neurosci. 31, 17250-17259. doi: 10. 1523/jneurosci.3938-11.2011

Weaver, A. K., Bomben, V. C., and Sontheimer, H. (2006). Expression and function of calcium-activated potassium channels in human glioma cells. Glia 54, 223-233. doi: 10.1002/glia.20364

Weaver, A. K., Liu, X., and Sontheimer, H. (2004). Role for calcium-activated potassium channels (BK) in growth control of human malignant glioma cells. J. Neurosci. Res. 78, 224-234. doi: 10.1002/jnr.20240

Wolle, D., Lee, S. J., Li, Z., Litan, A., Barwe, S. P., and Langhans, S. A. (2014). Inhibition of epidermal growth factor signaling by the cardiac glycoside ouabain in medulloblastoma. Cancer Med. 3, 1146-1158. doi: 10.1002/ cam 4.314

Wu, J., Akkuratov, E. E., Bai, Y., Gaskill, C. M., Askari, A., and Liu, L. (2013). Cell signaling associated with $\mathrm{Na}^{(+)} / \mathrm{K}^{(+)}$-ATPase: activation of phosphatidylinositide 3-kinase IA/Akt by ouabain is independent of Src. Biochemistry 52, 9059-9067. doi: 10.1021/bi4011804 
Xing, D., Wang, J., Ou, S., Wang, Y., Qiu, B., Ding, D., et al. (2014). Expression of neonatal $\mathrm{Na}_{V} 1.5$ in human brain astrocytoma and its effect on proliferation, invasion and apoptosis of astrocytoma cells. Oncol. Rep. 31, 2692-2700. doi: 10. 3892/or.2014.3143

Yang, M., Kozminski, D. J., Wold, L. A., Modak, R., Calhoun, J. D., Isom, L. L., et al. (2012). Therapeutic potential for phenytoin: targeting $\mathrm{Na}(\mathrm{v}) 1.5$ sodium channels to reduce migration and invasion in metastatic breast cancer. Breast Cancer Res. Treat. 134, 603-615. doi: 10.1007/s10549-012-2102-9

Yatime, L., Buch-Pedersen, M. J., Musgaard, M., Morth, J. P., Lund Winther, A. M., Pedersen, B. P., et al. (2009). P-type ATPases as drug targets: tools for medicine and science. Biochim. Biophys. Acta 1787, 207-220. doi: 10.1016/j.bbabio.2008. 12.019

Yip, D., Le, M. N., Chan, J. L., Lee, J. H., Mehnert, J. A., Yudd, A., et al. (2009). A phase 0 trial of riluzole in patients with resectable stage III and IV melanoma. Clin. Cancer Res. 15, 3896-3902. doi: 10.1158/1078-0432.ccr-08-3303
Zhang, Y., Wang, H., Qian, Z., Feng, B., Zhao, X., Jiang, X., et al. (2014). Lowvoltage-activated T-type $\mathrm{Ca}^{2+}$ channel inhibitors as new tools in the treatment of glioblastoma: the role of endostatin. Pflugers Arch. 466, 811-818. doi: 10. 1007/s00424-013-1427-5

Conflict of Interest Statement: The authors declare that the research was conducted in the absence of any commercial or financial relationships that could be construed as a potential conflict of interest.

Copyright (c) 2015 Litan and Langhans. This is an open-access article distributed under the terms of the Creative Commons Attribution License (CC BY). The use, distribution and reproduction in other forums is permitted, provided the original author(s) or licensor are credited and that the original publication in this journal is cited, in accordance with accepted academic practice. No use, distribution or reproduction is permitted which does not comply with these terms. 